\title{
Epidemiology of Colorectal Adenomas and Histopathological Assessment of Endoscopic Specimens in the Colorectum
}

\author{
Johanna Munding Andrea Tannapfel \\ Institut für Pathologie, Ruhr-Universität Bochum, Germany
}

\author{
Keywords \\ Colorectal polyp - Histopathological assessment . \\ Conventional adenoma $\cdot$ Serrated adenoma
}

\section{Summary}

Background: Colorectal cancer is one of the most frequently observed neoplasms in the world. It develops from intraepithelial neoplasia of the colorectal mucosa, and these precursor lesions are also known as adenoma. As the precursor lesion is known and can be detected easily, efficient screening strategies are available for a reliable prevention of colorectal adenocarcinoma, e.g. by colonoscopy. Methods: Literature databases (PubMed) were searched selectively for the keywords 'colorectal adenoma', 'epidemiology', and 'resection techniques'. The results are presented in the following text, also taking into account our own experience and the current S3 guidelines. Results: Endoscopic resection samples are one of the specimens most frequently assessed by pathologists. Therefore, gastroenterologists expect standardized and well-structured pathology reports, stating relevant information concerning the removed lesions and recommendations for clinical management. These aspects are summarized in the evidence-based S3 guideline. Conclusion: As a consequence of colorectal adenoma resection during screening procedures, the carcinoma incidence is decreasing. For further advancements in successful prevention, knowledge of different precursor lesions (conventional adenoma, serrated adenoma) is important, but also structured communication between the different disciplines engaged in colorectal cancer screening.
Schlüsselwörter

Kolorektaler Polyp - Histopathologische Aufarbeitung . Klassisches Adenom · Serratiertes Adenom

\section{Zusammenfassung}

Hintergrund: Das kolorektale Adenokarzinom ist eines der weltweit am häufigsten auftretenden Karzinome. Es entwickelt sich aus Vorläuferläsionen, den intraepitheliaIen Neoplasien der kolorektalen Schleimhaut, die auch als Adenome bezeichnet werden. Dadurch, dass die Vorläuferläsionen bekannt sind und leicht detektiert werden können, ist es möglich, ein effizientes Screening durchzuführen. Der Goldstandard der kolorektalen Krebsvorsorge ist die Koloskopie und die Abtragung der Vorläuferläsionen. Methoden: Eine Literaturdatenbankrecherche (PubMed) wurde durchgeführt und Artikel mit Bezug zu Epidemiologie und Resektion/Aufarbeitung kolorektaler Adenome wurden selektiv ausgewählt. Diese wurden auch unter Berücksichtigung eigener Erfahrungen und der aktuell gültigen S3-Leitlinie ausgewertet. Ergebnisse: Endoskopisch resezierte Polypen und kolorektale Biopsien sind mit das häufigste Untersuchungsgut der Pathologen. Im Gegenzug erwarten Gastroenterologen eine standardisierte und strukturierte Aufarbeitung und Befundung mit einer genauen Diagnose, aus der sich das weitere klinische Management ableiten lässt. Diese Anforderungen werden in der aktuellen Version der evidenzbasierten S3-Leitlinie zusammengefasst. Schlussfolgerung: Als Folge des Screenings nimmt die kolorektale Karzinominzidenz ab. Um diese Erfolge der Vorsorgeuntersuchungen weiter zu verbessern, ist die Kenntnis der verschiedenen Vorläuferläsionen (klassisches Adenom, serratierte Adenome) von wesentlicher Bedeutung, genauso wie eine gute und strukturierte interdisziplinäre Zusammenarbeit.

\section{KARGER \\ Fax +497614520714 \\ Information@Karger.com}

www.karger.com (c) 2014 S. Karger GmbH, Freiburg

$1662-6664 / 14 / 0301-0010 \$ 39.50 / 0$

Accessible online at:

www.karger.com/vim 


\section{Epidemiology}

Colorectal cancer is the third most prevalent cancer in the western world, accounting for up to $10 \%$ of the annual cancer incidence: It is the only major malignant disease with the same incidence rates in men and women [1-3]. The risk factors for development of colorectal adenocarcinoma can be divided into two classes. The first class comprises lifestyle factors such as unbalanced nutrition, i.e. a high-fat and low-fiber diet, little fresh fruit and vegetables, and a reduced folate uptake. Age above 50 years is another risk factor. The formation of colorectal carcinomas is further promoted by adipositas, high alcohol intake, nicotine abuse, and a generally sedentary lifestyle. The second class considers ethnicity, the patient's history of colorectal cancer (i.e. former adenomas), and a family history related to colorectal carcinomas (i.e. hereditary carcinomas) as an indicator for an increased cancer risk.

Additionally, hereditary cancer syndromes like familial adenomatosis polyposis coli or Lynch syndrome are also considered to be models of different colorectal adenoma carcinoma sequences, and the recently described hyperplastic polyposis syndromes such as MUTYH have high lifetime risks of up to $100 \%$ for the development of colorectal adenocarcinoma. Furthermore, Peutz-Jeghers syndrome, juvenile polyposis (Cowden/Gardner syndrome), hereditary mixed polyposis syndrome, and other hereditary cancer syndromes are also associated with colorectal adenocarcinoma. Moreover, patients with inflammatory bowel disease (i.e. colitis ulcerosa, and to a lesser extent Crohn's disease) exhibit an increased colorectal cancer incidence.

Screening procedures have proven to be an efficient tool to reduce colorectal cancer mortality by allowing the detection of malignant tumors at an early stage, and enable the removal of precursor lesions. Partly as a consequence of screening strategies, death from colorectal adenocarcinoma has declined in the last decade by over $2 \%$ per year in the USA. In Europe, a similar tendency was observed: the mortality declined for men by $1.6 \%(18.8 / 100,000$ per year) and by $2.5 \%$ per year for women between 1997 and 2002 [4-6].

Concordant with the improvements in screening strategies, changes in incidence rate, stage at diagnosis, mortality, and location (i.e. left-sided to right-sided colorectal carcinoma) have been reported over the last two decades. Apparently, related to the ageing population, the decreased incidence of left-sided cancer is more significant than a real increase in right-sided cancer which is more prevalent in the elderly, especially in women. Probably, this change, as well as differences in the molecular biology, can be attributed to the observations described, in combination with screening achievements and changes in lifestyle with different exposures to procarcinogenic agents in the proximal colon; at least, previous polypectomy is more likely in the distal colon than in the proximal colon. However, as a consequence of the ageing society, the economic burden of cancer treatment is suspected to increase, as colorectal adenocarcinoma, like most other malignant diseases, remains a disease of advanced age.

The National Polyp Study in the USA demonstrated that colonoscopy combined with polypectomy reduces the incidence of colorectal adenocarcinoma by more than $75 \%$ [7]. Additionally, impressive calculations were published in recent studies: They demonstrated for a birth cohort of 4 million individuals surveyed at the recommended screening intervals that 31,500 deaths would be prevented leading to an overall gain of 338,000 life years over the expected lifetime of the birth cohort. In the year 2000, the decrease in costs to the health insurance system associated with offering patients aged 50 years and older the choice of colorectal cancer screening was USD 11,900 per year of life gained [8].

Similarly to the USA, in Germany colorectal cancer screening is offered as a public health service to reduce economic burden and to ensure quality of life. Screening colonoscopy is offered to every person above 55 years, and is routinely repeated in 10-year intervals, depending on the results of the index colonoscopy. Alternatively, blood stool tests are repeated every 2 years [1, 2].

The incidence of precursor lesions of colorectal carcinoma depends on the surveying strategy. In colonoscopy-based studies, the prevalence is about $25 \%$; in sigmoidoscopy-based studies, it is at least $10 \%$. This represents the higher prevalence of colorectal adenomas in the left-sided hemicolon, which comprise about two thirds of all precursor lesions [9]. The incidence of colorectal adenoma is age-dependent, being lower in younger individuals and reaching a peak after the seventh decade of life. In autopsy studies, the incidence reaches $88 \%$ above the age of 80 years. In the sixth decade, the prevalence is already as high as $41-69 \%$. Men are more often affected than women, and $40 \%$ of patients in screening studies show more than one adenoma [9]. $2 \%$ of all asymptomatic patients undergoing screening colonoscopy show highgrade lesions, whereas $1 \%$ already has invasive disease.

Since the introduction of screening colonoscopy in 2002, about 100,000 colorectal carcinomas could be prevented, while 300,000 high-grade lesions were removed and about 50,000 asymptomatic colorectal cancers were diagnosed at an early stage (Union internationale contre le cancer (UICC) stage I/II) [10].

\section{Endoscopic Diagnostics/Specimens}

Complete colonoscopy is the gold standard for screening purposes. Different endoscopic techniques, in combination with polyp resection strategies, are reviewed in the following articles in this issue. Screening colonoscopy is a standardized procedure; therefore, certain standards are recommended for documentation, comparability for follow-up colonoscopy, and interdisciplinary cooperation between endoscopists, pathologists, and general practitioners. Table 1 summarizes the requirements for endoscopy reports. The pathohistological as- 
Table 1. Endoscopy reports: the following information should be listed in the endoscopic reports for complete colonoscopy (checklist modified from [14] where also a checklist for pathology reports is available)

\begin{tabular}{ll}
\hline Amount of polyps & single, multiple (number) polyposis \\
Morphology & according to the Paris classification: \\
& Ip (pedunculated); Is (sessile); IIa (flat-elevated); IIb (flat-flat), IIc (flat-depressed) \\
& LST-G (laterally spreading tumor, granulated type) \\
& LST-NG (laterally spreading tumor, non-granulated) \\
& conspicuous for sessile serrated adenoma \\
& submucosal lesion \\
& inflammatory non-neoplastic lesion \\
& not classified \\
& recurrent lesion \\
& part of the colorectum, height above anal canal \\
estimated size in mm \\
Size & snare/forceps polypectomy, piecemeal resection, sub-/mucosectomy \\
Resection procedure & macroscopically complete or incomplete resection, biopsy of larger lesions, all parts/partly \\
Resection status & recovered \\
bleeding, perforation, treatment necessary \\
\hline
\end{tabular}

sessment of the endoscopic findings remains mandatory, although several studies stated great improvements in endoscopic diagnostics. In the recent DISCARD (Detect Inspect Characterise Resect and Discard) study conducted in reference centers with specific interest in endoscopic imaging, the prediction of polyp histology by means of endoscopic pattern analysis was found to have an accuracy of more than $90 \%$ [11]. As a consequence, it has been suggested that for small lesions, endoscopic imaging techniques might be used for differential diagnosis to reduce workload and costs. In contrast to this, a large prospective study published in Gut in June 2013, based on private practice screening settings, also compared endoscopic and pathohistological diagnosis with polyp differential diagnosis as the main outcome [12]. In this study, latest generation colonoscopes were used, which yielded an accuracy, sensitivity, and specificity of the in vivo diagnoses of only 76.6, 78.1 , and $73.4 \%$, respectively. The in vivo diagnostic accuracy was thus much lower when compared to the previously published study mentioned above [13]. According to these observations, histological assessment is still absolutely necessary for correct post-polypectomy surveillance and diagnosis.

Due to modern endoscopic techniques, several methods for biopsy extraction or polyp resections are available. Even large lesions can be removed by endoscopic (sub-)mucosal dissection (EMD/ESD). As the risk of invasiveness increases with the size of the polyp, these lesions have to be analyzed very carefully. In all cases, relevant clinical information such as patient history, endoscopic appearance, and the exact anatomic site must be given as this information is essential for a correct and comprehensive diagnosis. Especially previous malignancies in the patient history have to be specified.

\section{Histopathological Assessment}

Histopathological assessment of endoscopic specimens depends on clinical information, size, and structure of the speci- mens. The pathology report will contain the procedure performed, and state the features present in the sample such as mucosa or submucosal structures, intraepithelial neoplasia, or invasive growth. If polypoid lesions are resected, the histological subtype such as neoplastic (adenomatous/malignant), hyperplastic, hamartomatous, or inflammatory will be stated. In the case of an adenomatous lesion, its structure is described as tubular, tubulovillous, villous, or serrated, and the intraepithelial neoplasia is graded as low- or high-grade. Additionally, the resection status (complete/incomplete) is discussed. The information concerning grading and resection margins is essential for follow-up recommendations, as carcinoma risk and local recurrence rate depend on resection status, size, morphology, and grade of the intraepithelial neoplasia. If invasive growth such as adenocarcinoma is detected, the invasion depth should be commented on, invasion of lymph or blood vessels should be indicated, and resection margins must be analyzed as described later.

\section{Histopathology of Polypoid Lesions}

Although endoscopic resection specimens or biopsies lack the size and complexity of more extensive bowel resections, they are delicate structures and require meticulous processing. In a routine setup, the number and size of the resected specimens should be stated. If complete polyps were resected or mucosectomies are available, their size and structure has to be described, whereas in pedunculated lesions the dimension of the base is of importance [14] (fig. 1).

As already mentioned, endoscopically polypoid appearing lesions can show different histological qualities (i.e. neoplastic (adenomatous/malignant), hyperplastic, hamartomatous or inflammatory); their characteristics are described in the following:

Inflammatory lesions such as inflammatory pseudopolyps, granulation tissue, or regenerative tissue can show a polypoid appearance endoscopically. Histologically, inflammatory 
Fig. 1. a Macroscopic picture of a formalinfixed pedunculated polyp. b, c Two slides showing two different resection methods: snare resection of a pedunculated lesion (b), histologically a tubulovillous adenoma with lowgrade intraepithelial neoplasia; piecemeal resection of a tubular adenoma with low-grade intraepithelial neoplasia (c).
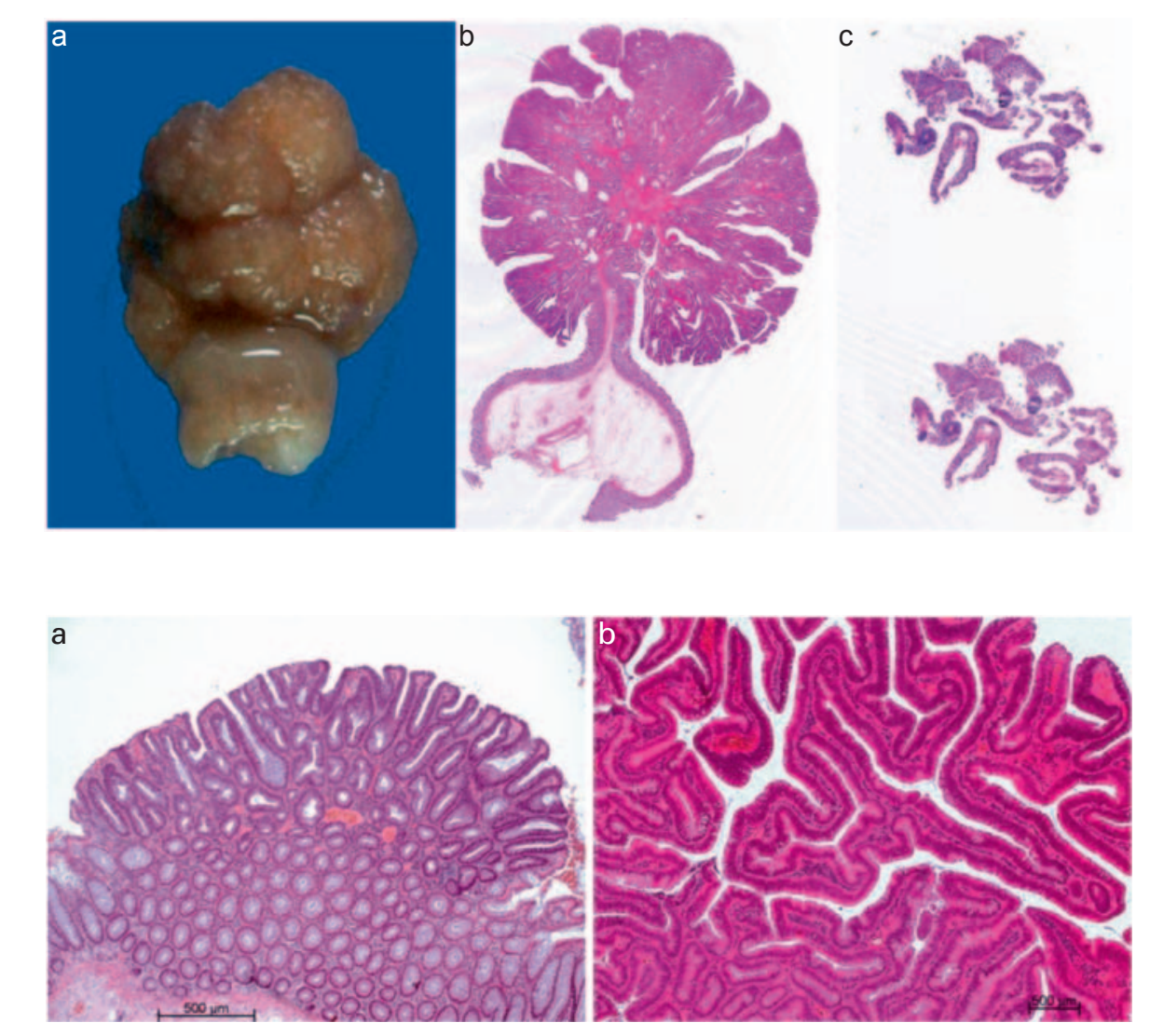

Fig. 2. Conventional colorectal adenoma. a Tubular adenoma with low-grade intraepithelial neoplasia. b Tubulovillous architecture of an adenoma with low-grade intraepithelial neoplasia.

Table 2. Follow-up recommendations (according to $[1,2]$ )

\begin{tabular}{ll}
\hline Histopathological findings at index colonoscopy & Interval to next screening colonoscopy \\
\hline Single non-neoplastic lesion (no hereditary disease known) & 10 years \\
1 or 2 conventional adenomas $<1 \mathrm{~cm}$ without high-grade intraepithelial neoplasia & 5 years \\
$3-10$ conventional adenomas or 1 adenoma $>1 \mathrm{~cm}$ or villous histology & 3 years \\
Single adenoma with high-grade intraepithelial neoplasia and complete resection (in pathology report) & 3 years \\
Histological incomplete resection, although macroscopically/endoscopically completely resected & $2-6$ months \\
$>10$ adenomas & $<3$ years, depending on family history \\
Resection of large or flat/sessile adenomas in piecemeal technique & $2-6$ months \\
If inconspicuous, next screening interval & 5 years \\
Histopathologically complete resection of traditional serrated adenoma, mixed polyp, or sessile & 3 years \\
$\quad$ serrated adenoma independent of grade of intraepithelial neoplasia & \\
Complete (R0) resection of low-grade; low-risk (sm1) adenocarcinoma & 6 months \\
If inconspicuous, next screening interval & 2 years \\
\hline
\end{tabular}

changes are present with regenerative and often hyperplastic epithelium, irregular crypt formation, and granulation tissue with many capillaries, fibroblasts, and inflammatory cells. The regenerative changes in the epithelium must be distinguished from neoplastic proliferation.

Hamartomatous polyps often develop in the context of hereditary diseases such as Peutz-Jeghers syndrome, or in patients with juvenile polyposis. Hamartomatous polyps as juvenile polyps and Peutz-Jeghers polyps display characteristic features like hyperplastic crypts and inflammatory changes or branching smooth muscle fibers ascending into the submucosa.
Adenomatous/preneoplastic lesions encompass adenomas, conventional tubular, tubulovillous and villous, as well as serrated adenomas, and intraepithelial neoplasia in cases of inflammatory bowel disease. The latter type of lesion is further classified as dysplasia-associated lesion or masses (DALM), flat intraepithelial neoplasia, or adenoma-like masses (ALM).

Conventional adenomas are defined by two histological key features: the architecture and the degree of intraepithelial neoplasia. The architectural pattern describes the proportion of tubular components, e.g. neoplastic epithelial glands surrounded by lamina propria and villous components containing the epithelial lining and the lamina propria. Tubular and vil- 
Fig. 3. Different subtypes of polypoid lesions in the colorectum. A Mucosal metastasis of a malignant melanoma in the rectum. B Juvenile polyp of the colon. C Peutz-Jeghers polyp. D-F Serrated lesions: D Hyperplastic polyp. E Traditional serrated adenoma. F Sessile serrated adenoma, each with low-grade intraepithelial neoplasia.
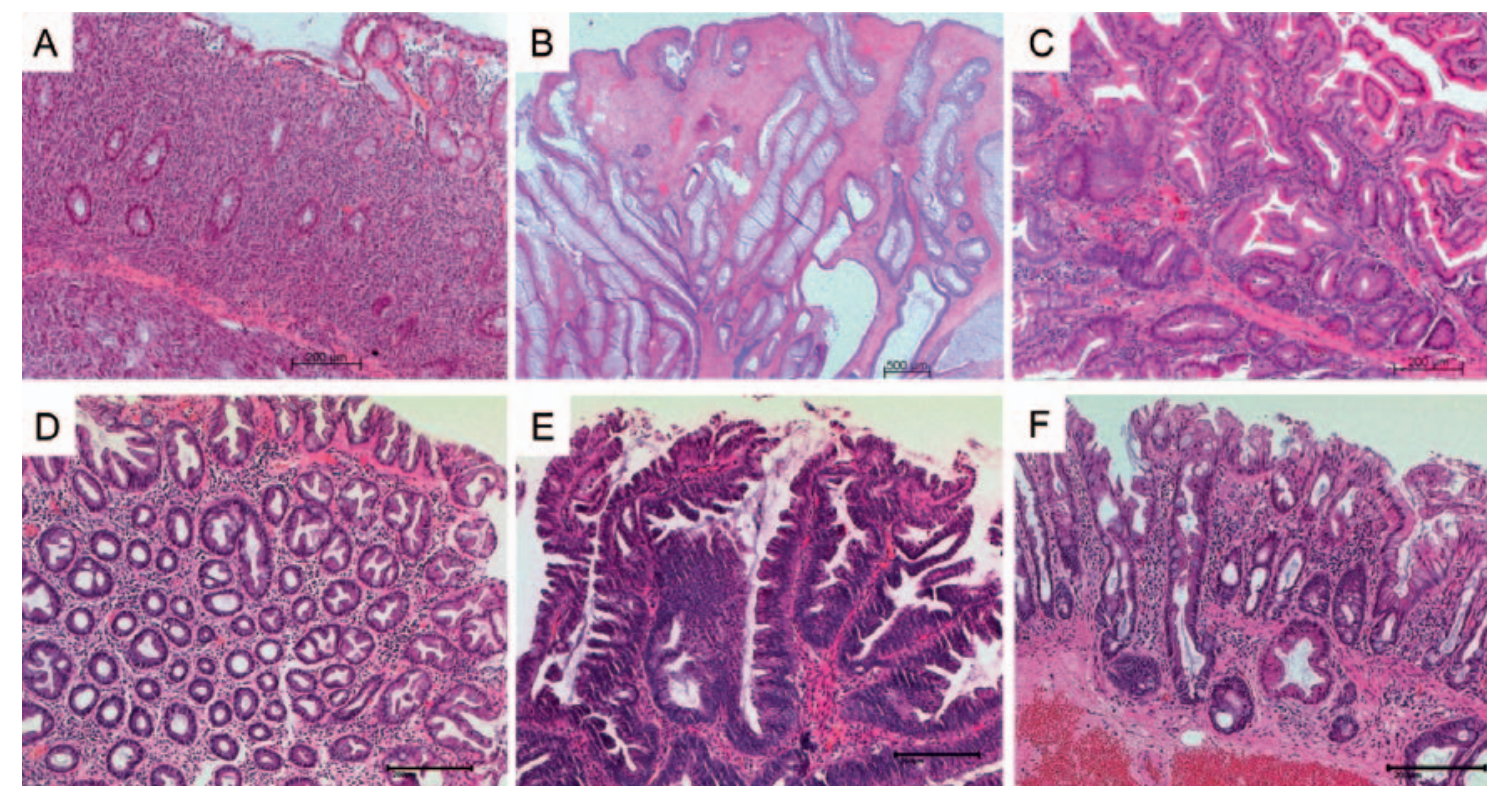

lous adenomas have per definition less than $20 \%$ villous or tubular components. Otherwise, the lesion is classified as a tubulovillous adenoma (fig. 2). The interobserver variability concerning this classification is quite high, but it is needed to determine the follow-up criteria (table 2). The degree of intraepithelial neoplasia depends on the cellularity, loss of cellular polarity and stratification, nuclear polymorphy/hyperchromasia, and crowding of adenoma cells.

Complete resection can be stated if non-dysplastic mucosa is present at the resection margins. In fragmented resection material, complete resection cannot be ascertained, although it might be histologically possible. In the report, this should be commented on. In these cases, complete resection should be evaluated depending on endoscopic findings.

Flat adenomas used to be more commonly described in Asian studies, but awareness of this type of lesion is increasing in the western world. Flat adenoma is usually defined as an elevation that is generally less than the height of a closed biopsy forceps $(2.5 \mathrm{~mm})$ or histologically less than twice the height of the adjacent mucosa. Rare cases can be situated at the level of the mucosa, or even be depressed. These lesions are more likely to display high-grade intraepithelial neoplasia or invasive growth.

\section{Serrated Lesions}

The so-called 'serrated polyp' was first described by Longacre and Fenoglio-Preiser in 1990 [15]. This subgroup of polypoid lesions is supposed to be the precursor of sporadic microsatellite-instable colorectal adenocarcinoma, and contains different heterogeneous structures all of which display a serrated morphology:

Hyperplastic polyps are distinguished from sessile and traditional serrated polyps/adenomas and mixed polyps contain- ing serrated and conventional adenoma in part. Hyperplastic polyps account for up to $75 \%$ of all serrated lesions, and are located in the left hemicolon, especially in the rectosigmoid. They are often multiple. Hyperplastic polyps are small symmetric lesions which can be classified into three different subtypes, namely, microvesicular (most frequent), goblet cellrich, and mucin-poor [16]. The microvesicular subtype often contains a BRAF mutation. This suggests that this is the probable precursor of sessile serrated adenomas. In contrast, goblet cell-rich subtypes lack BRAF mutations, but display KRAS mutations instead [17].

Sessile serrated adenomas/polyps comprise 1-9\% of all polypoid colorectal lesions. They are mostly located in the right hemicolon and are usually about $5 \mathrm{~mm}$ in size. As they are flat or sessile lesions often covered by a mucus cap, they are more difficult to detect endoscopically than conventional adenomas. Histologically, they show characteristic serration of crypts with basal architectural disturbances with branching and pseudoinvasion or inverted crypts [16].

Since the recognition of serrated lesions as a precursor of a distinct subtype of colorectal adenocarcinoma, the awareness concerning these lesions has increased. In recent studies, interobserver agreement for classification of sessile serrated adenomas was quite low [18]. This is partly due to the WHO definition of 2010: if as little as 2 or 3 contiguous crypts demonstrate features of sessile serrated adenoma in an otherwise hyperplastic-appearing polyp, the lesion should be classified as a sessile serrated adenoma [3, 19]. As mentioned above, basal crypt architecture is crucial for this classification. Therefore, biopsy technique and orientation in the pathohistological assessment are very important, and correct classification in small superficial biopsies can be impossible.

Traditional serrated adenomas are rare $(<1 \%$ of all intestinal polyps). They are more common in the left hemicolon 
Table 3. Subtypes of colorectal polypoid-appearing lesions (modified from [20])

\begin{tabular}{|c|c|}
\hline \multirow[t]{6}{*}{ Epithelial } & conventional adenoma (tubular tubulovillous villous) \\
\hline & flat adenoma \\
\hline & $\begin{array}{l}\text { serrated adenoma/polyp: sessile serrated adenoma, traditional serrated } \\
\text { adenoma }\end{array}$ \\
\hline & hyperplastic polyp (microvesicular, goblet cell-rich, mucin-poor) \\
\hline & mixed polyp \\
\hline & adenocarcinoma \\
\hline \multirow[t]{3}{*}{ Inflammatory } & $\begin{array}{l}\text { mucosal prolapse-associated polyp (includes polypoid prolapsing mu- } \\
\text { cosal fold, inflammatory cloacogenic polyp, inflammatory myoglandular } \\
\text { polyp, inflammatory cap polyp) }\end{array}$ \\
\hline & inflammatory pseudo-polyp, polypoid granulation tissue \\
\hline & infection-associated lesions (cytomegalovirus, schistosomiasis) \\
\hline \multirow[t]{3}{*}{ Hamartomatous } & $\begin{array}{l}\text { Peutz-Jeghers polyp } \\
\text { juvenile polyp }\end{array}$ \\
\hline & Cowden syndrome and Bannayan-Riley-Ruvalcaba syndrome \\
\hline & Cronkite-Canada syndrome \\
\hline \multirow[t]{11}{*}{ Stromal } & inflammatory fibroid polyp \\
\hline & fibroblastic polyp/perineurioma \\
\hline & Schwann cell hamartoma \\
\hline & neurilemmoma and nerve sheath tumor variants \\
\hline & ganglioneuroma \\
\hline & leiomyoma of muscularis mucosae \\
\hline & lipoma \\
\hline & lipohyperplasia of ileocecal valve \\
\hline & gastrointestinal stromal tumor \\
\hline & neurofibroma \\
\hline & granular cell tumor \\
\hline \multirow[t]{2}{*}{ Lymphoid } & prominent lymphoid follicle/rectal tonsil \\
\hline & lymphomatous polyposis \\
\hline Neuroendocrine & $\begin{array}{l}\text { neuroendocrine tumors (well differentiated neuroendocrine tumor } \\
\text { (NET G1; 'carcinoid'), intermediate or poorly differentiated/small cell } \\
\text { neuroendocrine carcinoma) }\end{array}$ \\
\hline \multirow[t]{7}{*}{ Other } & prominent mucosal fold \\
\hline & everted appendiceal stump or cecal diverticulum \\
\hline & elastotic (elastofibromatous) polyp \\
\hline & endometriosis \\
\hline & mucosal xanthoma \\
\hline & melanoma/clear cell sarcoma \\
\hline & metastasis \\
\hline
\end{tabular}

and are polypoid. Histologically, they are also serrated, but exhibit a more villous histology with eosinophilic cytoplasm of the neoplastic epithelium and intraepithelial microazini (fig. 3).

\section{Submucosal Lesions}

Also, quite often submucosal mesenchymal lesions, or neuroendocrine tumors, and rarely mucosal metastases, are suggestive of polypoid lesions endoscopically. In these cases, clinical information is even more important. In addition to conventional hematoxylin/eosin staining of histological sections, immunohistochemistry is necessary for diagnosis in those cases. Examples of these lesions are listed in table 3 .

\section{Invasive Adenocarcinoma}

The rate of adenocarcinoma detection in polypoid lesions depends on the size of the polypoid lesion. In diminutive polyps $(<5 \mathrm{~mm})$, less than $2 \%$ display advanced features such as high-grade intraepithelial neoplasia, and these are almost never associated with carcinoma [15]. Small lesions, 5-10 mm in diameter, display advanced features in $10 \%$, and invasion of the submucosa in almost $1 \%$ of cases. In conventional villous adenoma, invasive growth is present in more than $50 \%$ of patients, summing up to an overall incidence of invasive adenocarcinoma in $4.7 \%$ of all polypectomies [7].

If invasive growth is present in a polypectomy specimen, the precursor lesion must be described. The grading (lowgrade $(\mathrm{G} 1, \mathrm{G} 2)$ vs. high-grade $(\mathrm{G} 3, \mathrm{G} 4))$ and histological subtype of the adenocarcinoma (e.g. mucinous, signet ring cells 
etc.) is stated, as well as the presence of invasion of submucosal or deeper structures. As the risk of lymphatic spread correlates with the invasion depth, in the case of submucosal invasion the invasion depth should be measured quantitatively $(\mu \mathrm{m})$ in the resection specimen and indicated in the pathology report. For the risk assessment, the submucosal level is subdivided into thirds. Invasion of the upper third or of the polyp base of a pedunculated polyp is labeled as sm1 and considered as low risk. Together with sm2-adenocarcinomas, which show invasion of the middle third of the submucosa, the risk of lymphatic metastasis is only $0-6 \%$, while in sm3lesions, with invasion of the lower third, lymphatic metastasis is present in $20 \%$. These lesions are considered as high risk. Additionally, invasion into lymphatic vessels is generally categorized as high risk. Invasion into blood vessels should also be stated. As in adenomatous lesions, the resection margin has to be assessed, and the distance of the carcinoma to the resection margin has to be measured quantitatively in $\mu \mathrm{m}$.

Concerning further therapy, it is important to classify endoscopically completely resected $\mathrm{T} 1$-adenocarcinoma as low- risk (G1/G2 and L0, R0) or high-risk lesions (G3/G4 and/or L1 and/or R1). In low-risk situations, no further oncological resection is necessary $[1,2]$.

\section{Conclusion}

In summary, correct assessment of endoscopic specimens in the colorectum requires close interaction between the endoscopist and the pathologist, each depending on the information provided by the other. In the pathology report, histological subtype, grade of intraepithelial neoplasia, and presence of invasive growth should be stated. In the case of invasive adenocarcinoma, the risk of local lymphatic spread must also be included [14].

\section{Disclosure Statement}

No conflicts of interest.

\section{References}

1 Pox C, Aretz S, Bischoff SC, et al: S3-guideline colorectal cancer version 1.0 (article in German). Z Gastroenterol 2013;51:753-854.

2 Schmiegel W, Reinacher-Schick A, Arnold D, Graeven U, Heinemann V, Porschen R, Riemann J, Rodel C, Sauer R, Wieser M, Schmitt W, Schmoll HJ, Seufferlein T, Kopp I, Pox C: Update S3-guideline 'colorectal cancer' 2008 (article in German). Z Gastroenterol 2008;46:799-840.

3 Bosman FT, Carneiro F, Hruban RH (eds): WHO Classification of Tumours of the Digestive System, ed 4. Lyon, IARC, 2010.

$\checkmark 4$ Gupta AK, Melton LJ 3rd, Petersen GM, Timmons LJ, Vege SS, Harmsen WS, Diehl NN, Zinsmeister $\mathrm{AR}$, Ahlquist DA: Changing trends in the incidence, stage, survival, and screen-detection of colorectal cancer: a population-based study. Clin Gastroenterol Hepatol 2005;3:150-158.

$\checkmark 5$ Jemal A, Siegel R, Ward E, Hao Y, Xu J, Murray T, Thun MJ: Cancer statistics, 2008. CA Cancer J Clin 2008;58:71-96.

6 Golfinopoulos V, Salanti G, Pavlidis N, Ioannidis JP: Survival and disease-progression benefits with treatment regimens for advanced colorectal cancer: a meta-analysis. Lancet Oncol 2007;8:898-911.

7 Winawer SJ, Zauber AG, Ho MN, et al: Prevention of colorectal cancer by colonoscopic polypectomy. The National Polyp Study Workgroup. N Engl J Med 1993;329:1977-1981.
8 Maciosek MV, Solberg LI, Coffield AB, Edwards NM, Goodman MJ: Colorectal cancer screening: health impact and cost effectiveness. Am J Prev Med 2006;31:80-89.

9 Stolte M, Rüschoff J, Klöppel G (eds): Verdauungstrakt und Peritoneum. Berlin/Heidelberg, Springer, 2013

10 Brenner H, Altenhofen L, Hoffmeister M: Estimated long-term effects of the initial 6 years of the German screening colonoscopy program. Gastrointest Endosc 2010;72:784-789.

11 Ignjatovic A, East JE, Suzuki N, Vance M, Guenther T, Saunders BP: Optical diagnosis of small colorectal polyps at routine colonoscopy (Detect InSpect ChAracterise Resect and Discard; DISCARD trial): a prospective cohort study. Lancet Oncol 2009;10:1171-1178.

12 Schachschal G, Mayr M, Treszl A, Balzer K, Wegscheider K, Aschenbeck J, Aminalai A, Drossel R, Schroder A, Scheel M, Bothe CH, Bruhn JP, Burmeister W, Stange G, Bahr C, Kiesslich R, Rosch $\mathrm{T}$ : Endoscopic versus histological characterisation of polyps during screening colonoscopy. Gut 2013;DOI:10.1136/gutjnl-2013-304562.

13 Ladabaum U, Fioritto A, Mitani A, Desai M, Kim JP, Rex DK, Imperiale T, Gunaratnam N: Realtime optical biopsy of colon polyps with narrow band imaging in community practice does not yet meet key thresholds for clinical decisions. Gastroenterology 2013;144:81-91.
14 Baretton GB, Tannapfel A, Schmitt W: Standardized and structured histopathological evaluation of colorectal polyps: a practical checklist against the background of the new WHO classification (article in German). Pathologe 2011;32:289-296.

15 Longacre TA, Fenoglio-Preiser CM: Mixed hyperplastic adenomatous polyps/serrated adenomas. A distinct form of colorectal neoplasia. Am J Surg Pathol 1990;14:524-537.

16 Torlakovic E, Skovlund E, Snover DC, Torlakovic G, Nesland JM: Morphologic reappraisal of serrated colorectal polyps. Am J Surg Pathol 2003;27:65-81.

17 Yang S, Farraye FA, Mack C, Posnik O, O'Brien MJ: BRAF and KRAS mutations in hyperplastic polyps and serrated adenomas of the colorectum: relationship to histology and $\mathrm{CpG}$ island methylation status. Am J Surg Pathol 2004;28:1452-1459.

18 Glatz K, Pritt B, Glatz D, Hartmann A, O'Brien MJ, Blaszyk H: A multinational, internet-based assessment of observer variability in the diagnosis of serrated colorectal polyps. Am J Clin Pathol 2007; 127:938-945.

19 Rosty C, Hewett DG, Brown IS, Leggett BA, Whitehall VL: Serrated polyps of the large intestine: current understanding of diagnosis, pathogenesis, and clinical management. J Gastroenterol 2013;48:287-302.

20 Shepherd NA, Warren BF, Williams GT, Greenson JK, Lauwers GY, Novelli MR (eds): Morson and Dawson's Gastrointestinal Pathology. London, Wiley-Blackwell, 2013. 